"2016 ESC Guidelines for the diagnosis and treatment of acute and chronic heart failure ", Eur J Heart Fail, 18(8), pp. 891-975

5. Komajda M., Cowie M. R., et al. (2017), "Physicians' guideline adherence is associated with better prognosis in outpatients with heart failure with reduced ejection fraction: the QUALIFY international registry", Eur J Heart Fail, 19(11), pp. 1414-1423.

6. Chang H. Y., Wang C. C., et al. (2017), "Gap between guidelines and clinical practice in heart failure with reduced ejection fraction: Results from TSOC-HFrEF registry", J Chin Med Assoc, 80(12), pp. 750-757.

\title{
ẢNH HƯởNG CỦA HộI CHỨNG CHUYỂN HÓA ĐẾN KÍCH THƯớC VÀ CHỨC NĂNG NHĨ TRÁI Ở BÊNH NHÂN SUY TIM Có PHÂN SUẤT TỐNG MÁU THẤT TRÁI $\geq 40 \%$
}

\author{
Vũ Thị Trang ${ }^{1}$, Nguyễn Thị Bạch Yến ${ }^{2}$, Trịnh Việt Hà ${ }^{3}$ \\ Phạm Tuấn Việt ${ }^{3}$, Lê Thanh Bình ${ }^{3}$
}

\section{TÓM TẮT}

Nghiên cứu quan sát mô tả loạt ca bệnh, có so sánh với nhóm chứng được thực hiên tại bênh viên Bach Mai trên 97 bênh nhần bị suy tìm có phân suất tổng máu thất trái $\geq 40 \%$ (có và không có hội chứng chuyển hóa) và 32 người thuộc nhóm chứng. Kết quả nghiên cứu ghi nhân: Các thông số siêu âm về thất trái, thất phải, chức năng tâm thu, chức năng tâm trương của các bênh nhân có và không có $\mathrm{HCCH}$ tương đương nhau. Bệnh nhân suy tim phân suất tống máu $\geq 40 \%$ kèm HCCH thì chỉ số thể tích nhĩ trái tối thiểu có xu hướng lớn hơn những bệnh nhân không bị $\mathrm{HCCH}$. Các phân suất làm rỗng nhĩ trái ở nhóm có $\mathrm{HCCH}$ thấp hơn nhóm không có $\mathrm{HCCH}$. Chức năng dẫn máu, tống máu và chứa máu của nhĩ trái có xu hướng thấp hơn ở nhóm có phân độ NYHA trâm trọng hơn. Khi thất trái càng giãn và càng dày, chỉ số đường kính nhĩ trái và các chỉ số thể tích nhĩ trái có xu hướng tăng lên. Có mối tương quan tuyến tính nghịch biến giữa chức năng chứa máu nhĩ trái với chỉ số khối cơ thể (BMI) theo phương trình: $\mathrm{Y}=-0.91$. BMI + 78.91.

Tư khóa: kích thước - chức năng nhĩ trái, hội chứng chuyển hóa, suy tim phân suất tống máu $\geq 40 \%$

\section{SUMMARY}

\section{EFFECTS OF THE TRANSFORMATION SYMPTOMS ON SMALL LEFT SIZE AND FUNCTION IN PATENTS WITH HEART FAILURE WITH LEFT VENTRICULAR EJECTION FRACTION $\geq \mathbf{4 0} \%$}

A descriptive observational study of a case series with comparison with a control group, was performed at Bach Mai hospital on 97 patients with heart failure with left ventricular ejection fraction $\geq 40 \%$ (with and

\footnotetext{
${ }^{1}$ Bệnh viện Hữu nghị Việt Tiệp Hải Phòng,

Bệnh viện Đa khoa Tâm Anh

${ }^{3}$ Viên Tim mach Viêt Nam-Bênh viên Bach Mai.

Chịu trách nhiệm chính: Vũ Thị Trang

Email: vuthitrang.vthp@gmail.com

Ngày nhận bài: 14.9.2021

Ngày phản biện khoa học: 3.11.2021

Ngày duyệt bài: 15.11.2021
}

without the syndrome)and 32 in the control group. Results: The ultrasound parameters of left ventricle, right ventricle, systolic function, diastolic function of patients with and without $\mathrm{HCCH}$ were similar. In patients with heart failure with an ejection fraction $\geq$ $40 \%$ with atrial fibrillation, the left atrial volume index tends to be greater than in patients without atrial fibrillation. The fractions of left atrial emptying in the group with $\mathrm{HCCH}$ were lower than in the group without $\mathrm{HCCH}$. The function of blood flow, ejection, and blood storage of the left atrium tended to be lower in the group with more severe NYHA class. As the left ventricle is dilated and thickened, the left atrial diameter index and the left atrial volume index tend to increase. There is a negative linear correlation between left atrial blood storage function and body mass index (BMI) according to the equation: $Y=$ 0.91. BMI + 78.91.

Key words: size - left atrial function, metabolic syndrome, heart failure ejection fraction $\geq 40 \%$

\section{I. ĐĂT VẤN ĐỀ}

Suy tim (ST) là hội chứng thường gặp trong lâm sàng, là hậu quả của nhiêu bệnh lý tim mạch. Tình trạng suy tim có mối liên quan đáng kể với sư thay đổi kích thước và chức năng nhĩ trái $(\mathrm{NT})^{(1)}$. Hội chứng chuyển hóa $(\mathrm{HCCH})^{(2)}$ là một nhóm các tình trạng bao gôm tăng huyết áp (THA), thừa mõ quanh vòng eo, tăng lipid máu, ...Hội chứng chuyển hóa ảnh hưởng lớn đến cấu trúc và chức năng tim mạch, trong đó có kích thước và chức năng nhĩ trái(3)

Các nghiên cứu chỉ ra rằng khi có hội chứng chuyển hóa, tình trạng biến đổi cấu trúc và chức năng nhĩ trái ở các bệnh nhân suy tim trở nên trầm trọng hơn. Chính vì vậy, chúng tôi đặt vấn đề nghiên cứu "Ảnh hưởng của hội chứng chuyển hóa đến kích thước và chức năng nhĩ trái ở bệnh nhân suy tim có phân suất tônng máu thất trái $\geq 40 \%$ với 2 mục tiêu:

1.Tìm hiêu đặc điểm kích thước, chức năng nhĩ trái ở bệnh nhân suy tim có phân suất tông 
máu thất trái $\geq 40 \%$ có và không có hội chứng chuyển hóa.

2. Tim hiêu mối liên quan giữa kích thước, chức năng nhĩ trái với một số dấu hiệu lâm sàng và cận lâm sàng ở các đối tượng trên.

\section{II. ĐỐI TƯỢNG VÀ PHƯƠNG PHÁP NGHIÊN CỨU \\ 2.1 Đối tượng nghiên cứu}

Tiêu chuân lứa chon. 97 bênh nhân suy tim với phân suất tống máu thất trái $(\mathrm{EF}) \geq 40 \%$, trong đó 51 bệnh nhân có $\mathrm{HCCH}, 46$ bệnh nhân không có $\mathrm{HCCH}$; 32 bệnh nhân nhóm chứng không bị suy tim và không có $\mathrm{HCCH}$.

Tiêu chuẩn chẩn đoán suy tim theo ESC 2016(4)

Tiêu chuẩn chẩn đoán hội chứng chuyển hóa theo NCEP/ATPIII ${ }^{(5)}$ : bệnh nhân phải có ít nhất 3 trong 5 tiêu chuẩn: Béo bụng (vòng eo $\geq 94 \mathrm{~cm}$ đối với nam và $\geq 80 \mathrm{~cm}$ đối với nữ); Triglycerid (TG) máu $\geq 1.7 \mathrm{mmol} / \mathrm{l}$; HDL-Cholesterol (HDLChol) máu $<1.0 \mathrm{mmol} / /$ đối với nam và $<1.3$ mmol/l đối với nữ; huyết áp $\geq 130 / 80$ hoă̆c hạ huyết áp; đường huyết lúc đói $\geq 6.1 \mathrm{mmol} / \mathrm{l}$.

Tiêu chuấn loại trừ. Bệnh nhân suy tim nặng mất bù, có hội chứng động mạch vành cấp chưa được điều trị ổn định, có bệnh van tim thực tổn, rung nhĩ.

2.2 Thời gian và địa điểm nghiên cứu. Nghiên cứu được tiến hành từ $1 / 8 / 2020$ đến 31/8/2021 tại bệnh viện Bạch Mai.

Thiết kế nghiên cứu. Phương pháp quan sát mô tả loạt ca bệnh, có phân tích so sánh đối chứng
Cỡ mẫu và chọn mẫu. Áp dụng công thức tính cõ mẫu cho bài toán so sánh 2 chỉ số trung bình của 2 nhóm đối tượng, tính được cõ mẫu 52 bệnh nhân có và không có $\mathrm{HCCH}$.

Trong thời gian nghiên cứu chọn được 97 bệnh nhân bị suy tim, 32 bệnh nhân thuộc nhóm chứng.

2.2 Phương pháp thu thâp thông tin. Phương pháp tiến cứu, kết quả được ghi chép theo bệnh án nghiên cứu, có tham khảo các thông tin cũ của bệnh nhân trong quá trình tuyển lựa đối tượng nghiên cứu.

Phân tích số liệu. Số liệu được xử lý bằng thuật toán thống kê theo phần mềm SPSS 16.0

Biến liên tục biểu thi bằng trung bình \pm đô lệch chuẩn, biến nhị phân biểu thị bằng tỷ lệ phần trăm

Phân tích liên quan: Sử dụng thuật toán hồi quy logistic.

So sánh tìm sự khác biệt giữa các nhóm: Sử dụng kiểm định Chi-square ( $x^{2}$ ), Fisher's Exact.

So sánh giá trị trung bình bằng quy luật Student, ANOVA với biến chuẩn, với biến không chuẩn dùng thuật toán Mann-Whitney, KruskalWallis và Wilcoxon.

Sự khác biệt được coi là có ý nghĩa thống kê khi $p<0,05$.

Đạo đức nghiên cứu. Nghiên cứu được cấp giấy chứng nhâan bởi Hội đồng Đạo đức $Y$ học trường Đại học Y Hà Nội(năm 2020)

\section{KẾT QUẢ NGHIÊN CỨU}

3.1 Đặc điểm lâm sàng và sinh hóa của các đối tượng trong nghiên cứu

Bảng 1. Đặc điểm lâm sàng và sinh hóa của các nhóm

\begin{tabular}{|c|c|c|c|}
\hline Tiêu chí & $\begin{array}{c}\text { Nhóm chứng } \\
(\mathbf{n}=\mathbf{3 2})\end{array}$ & $\begin{array}{c}\text { ST không HCCH } \\
(\mathbf{n}=\mathbf{4 6})\end{array}$ & $\begin{array}{c}\text { ST có HCCH } \\
(\mathbf{n}=\mathbf{5 1})\end{array}$ \\
\hline Tuối & $67.59 \pm 6.47$ & $70.22 \pm 10.50$ & $68.65 \pm 11.5$ \\
\hline Giới (tỷ lệ nữ \%) & 40.6 & 39.1 & 39.2 \\
\hline THA (\%) & 62.5 & 56.5 & $94.1++$ \\
\hline Tiếu đướng (\%) & $50.0^{* *}$ & 30.4 & $84.3++$ \\
\hline Glucose máu (mmol/l) & $6.0 \pm 2.61 * *$ & $70.22 \pm 10.50$ & $8.33 \pm 2.78++$ \\
\hline Mức lọc cầu thận (ml/p) & $68.44 \pm 18.68$ & $60.60 \pm 22.05$ & $66.59 \pm 30.65$ \\
\hline Chol-TP (mmol/l) & $4.83 \pm 1.43$ & $4.81 \pm 1.57$ & $4.77 \pm 1.89$ \\
\hline TG (mmol/l) & $2.08 \pm 2.54$ & $1.47 \pm 1.03$ & $4.14 \pm 3.12++$ \\
\hline BMI (kg/m2) & $22.21 \pm 2.54$ & $21.96 \pm 2.87$ & $24.69 \pm 2.85++$ \\
\hline BSA (m2) & $1.59 \pm 0.13$ & $1.57 \pm 0.14$ & $1.64 \pm 0.17++$ \\
\hline
\end{tabular}

*: Khác biệt giữa nhóm chứng và nhóm ST với $\mathrm{p}<0.05$

**: Khác biêt giữa nhóm chứng và nhóm STvới $\mathrm{p}<0.01$

+: Khác biệt giữa nhóm ST không HCCH và ST có $\mathrm{HCCH}$ với $p<0.05$

++ : Khác biệt giữa nhóm ST không $\mathrm{HCCH}$ và $\mathrm{ST}$ có $\mathrm{HCCH}$ với $\mathrm{p}<0.01$

Các thông số chung về lâm sàng của nhóm chứng và nhóm bệnh nhân suy tim không có khác biệt. Trừ nồng độ Glucose và tỷ lệ mắc tiểu đường.

Nhóm suy tim kèm HCCH có tiền sử tiểu đường, tăng huyết áp, chỉ số khối cơ thể, diện tích da, nồng độ Glucose và Triglycerid máu khác biệt rõ so với nhóm không có HCCH. 
3.2 Đặc điểm siêu âm tim của nhóm đối tượng nghiên cứu

Bảng 2. Đặc điểm siêu âm tim của các nhóm

\begin{tabular}{|c|c|c|c|}
\hline Thông số & $\begin{array}{l}\text { Nhóm chứng } \\
(n=32)\end{array}$ & $\begin{array}{c}\text { ST không HCCH } \\
(n=46)\end{array}$ & $\begin{array}{c}\text { ST có HCCH } \\
(n=51)\end{array}$ \\
\hline \multicolumn{4}{|c|}{ Cấu trúc và chức năng tâm thu thất trái } \\
\hline $\mathrm{Dd}(\mathrm{mm})$ & $43.84 \pm 5.04 *$ & $46.52 \pm 5.94$ & $47.16 \pm 6.44$ \\
\hline Ds (mm) & $26.84 \pm 3.94 * *$ & $30.61 \pm 7.79$ & $31.63 \pm 6.84$ \\
\hline $\mathrm{Vd}(\mathrm{mm})$ & $88.62 \pm 23.08 * *$ & $103.46 \pm 31.27$ & $105.96 \pm 32.76$ \\
\hline Vs (mm) & $27.81 \pm 10.06^{* *}$ & $40.8 \pm 27.59$ & $42.63 \pm 22.01$ \\
\hline IVSd (mm) & $8.31 \pm 1.66^{* *}$ & $10.11 \pm 2.26$ & $9.8 \pm 2.49$ \\
\hline IVSs (mm) & $11.59 \pm 2.46^{* *}$ & $13.37 \pm 2.69$ & $12.92 \pm 2.88$ \\
\hline LVPWd (mm) & $8.66 \pm 1.47^{* *}$ & $9.52 \pm 1.95$ & $9.88 \pm 1.83$ \\
\hline LVPWs(mm) & $13.07 \pm 2.17^{* *}$ & $14.26 \pm 2.77$ & $14.57 \pm 2.99$ \\
\hline EF Simpson Biplane (\%) & $66.69 \pm 5.86 * *$ & $59.8 \pm 11.28$ & $57.31 \pm 10.94$ \\
\hline LVmass Index $(\mathrm{g} / \mathrm{m} 2)$ & $76.64 \pm 21.74 * *$ & $105.94 \pm 38.12$ & $104.78 \pm 41.5$ \\
\hline LVVd Index (ml/m2) & $55.74 \pm 13.77^{* *}$ & $66.72 \pm 23.14$ & $65.64 \pm 23.61$ \\
\hline \multicolumn{4}{|c|}{ Chức năng tâm trương thất trái } \\
\hline $\mathrm{A}(\mathrm{cm} / \mathrm{s})$ & $67.16 \pm 16.14 *$ & $80.13 \pm 24.13$ & $72.00 \pm 18.46$ \\
\hline$E / A$ & $0.98 \pm 0.28$ & $0.99 \pm 0.44$ & $1.1 \pm 0.43$ \\
\hline $\mathrm{e}^{\prime}$ vách $(\mathrm{cm} / \mathrm{s})$ & $6.29 \pm 1.57^{* *}$ & $4.52 \pm 1.36$ & $4.31 \pm 1.02$ \\
\hline $\mathrm{e}^{\prime}$ bên $(\mathrm{cm} / \mathrm{s})$ & $8.27 \pm 1.73 * *$ & $5.8 \pm 1.95$ & $5.83 \pm 1.42$ \\
\hline \multicolumn{4}{|c|}{ Kích thước và chức năng nhĩ trái } \\
\hline Chỉ số đường kính NT (mm/m2) & $20.34 \pm 2.5^{* *}$ & $22.47 \pm 3.22$ & $22.04 \pm 3.68$ \\
\hline Thể tích NT trước co (ml) & $22.93 \pm 10.25^{* *}$ & $35.93 \pm 10.04$ & $36.76 \pm 14.94$ \\
\hline Thể tích NT lớn nhất (ml) & $34.1 \pm 15.0 * *$ & $50.59 \pm 14.62$ & $49.94 \pm 20.30$ \\
\hline Thể tích NT nhỏ nhất (ml) & $12.69 \pm 7.06^{* *}$ & $20.06 \pm 5.98$ & $24.12 \pm 10.31+$ \\
\hline Chức năng dần máu NT & $32.94 \pm 7.83 * *$ & $28.71 \pm 4.63$ & $26.23 \pm 5.18+$ \\
\hline Chức năng tống máu NT & $45.93 \pm 10.39 * *$ & $44.25 \pm 4.89$ & $34.5 \pm 9.3++$ \\
\hline Chức năng chứa máu NT & $63.95 \pm 6.75^{* *}$ & $60.21 \pm 4.87$ & $51.78 \quad 7.07++$ \\
\hline
\end{tabular}

Hầu hết các thông số siêu âm của nhóm chứng và nhóm bệnh có sự khác biệt. So sánh nhóm suy tim có và̀ không có $\mathrm{HCCH}$ chỉ ghi nhận sự khác biệt về chức năng và thể tích nhĩ trái nhỏ nhất.

3.3 Mối liên quan giữa kích thước, chức năng nhĩ trái của các đối tượng trong nghiên cứu với một số dấu hiệu lâm sàng, cận lâm sàng

*Kểt quả phân tích hồi quy tuyến tính đa biến và đơn biến ghi nhận

- Các yếu tố đóng góp vào sự biến đổi của các chỉ số kích thước, chức năng

nhĩ trái gồm: vòng bụng, chỉ số khối cơ thể, chỉ số khối cơ thất trái, chức năng tâm thu thất trái (Teicholz), chỉ số thể tích thất trái. biến

- Một số phương trình hồi quy tuyến tính đơn

Chỉ số đường kính NT=0.68. VdIndex +17.45

Chỉ số đường kính NT $=0.04$. LVmassIndex + 18.16

Chỉ số thể tích NT trước co $=0.09$. LVmassIndex +11.72

Chỉ số thể tích Nt lớn nhất $=0.12$. LVmassIndex +17.39
Chỉ số thể tích NT nhỏ nhất $=0.06$. LVmassIndex +6.23

Phân suất làm rỗng toàn bộ $\mathrm{NT}=-0.91$. BMI $+78.91$

*Chức năng tống máu và chức năng chứa máu NT ở nhóm khó thở (NYHA $\geq \mathrm{II}$ ) thấp hơn nhóm không khó thở (NYHA I): $36.86 \pm 8.8$ và $53.92 \pm 7.26$ so với $44.71 \pm 6.68$ và $60.34 \pm 5.7$ $(p<0.01)$.

*Chức năng tống máu và chức năng chứa máu NT của nhóm thừa cân - béo phì (BMI $\geq 25$ ) thấp hơn nhóm không thừa cân béo phì: $34.31 \pm$ 9.11 và $52.35 \pm 6.64$ so với $41.17 \pm 8.12$ và $57.24 \pm 7.29(p<0.01)$.

\section{BÀN LUẬN}

Các thông số đường huyết và lipid máu của nhóm ST có và không có HCCH khác nhau rõ rệt, điều này phù hợp với đặc điểm của $\mathrm{HCCH}$. Nhóm bệnh có chứa các bệnh nhân bị $\mathrm{HCCH}$, các thông số trên lớn hơnso với nhóm chứng nhưng có thể do cõ mẫu chưa đủ lớn nên sự khác biệt không có ý nghĩa thống kê.

Các thông số siêu âm tim của nhóm chứng và 
nhóm bệnh có khác biệt, đặc biệt các thông số về tâm trương thất trái. Điều này phù hợp vì đó là các tiêu chuẩn để chẩn đoán suy tim với phân suất tống máu thất trái $\geq 50 \%$ (vốn chiếm đa số trong các đối tượng nghiên cứu).

Các thông số siêu âm của nhóm suy tim có và không có $\mathrm{HCCH}$ chỉ ghi nhận sự khác biệt về thể tích nhĩ trái nhỏ nhất và chức năng dẫn máu tống máu - chứa máu của nhĩ trái. Ngoài ra không ghi nhận khác biệt về cấu trúc, chức năng tâm thu và tâm trương thất trái. Kết quả này phù hợp với một số tác giả khác ${ }^{(6,7)}$ (nghiên cứu trên các đối tượng tương tự).

Ngoài các yếu tố đóng góp vào mô hình hồi quy tuyến tính đa biến ở trên, một số yếu tố khác được dự đoán có đóng góp lớn nhưng cuối cùng khổng đưa được vào xây dựng mô hình do không có phân phối chuẩn. Một số biến cũng không đưa vào phân tích đơn biến được do không có phân phối chuẩn.

\section{KẾT LUẦN}

5.1. Đặc điểm kích thước, chức năng nhĩ trái ở bệnh nhân suy tim phân suất tống máu thất trái $\geq 40 \%$ có và không có hội chứng chuyển hóa

- Các thông số siêu âm về thất trái, thất phải, chức năng tâm thu, chức năng tâm trương của các bệnh nhân có và không có $\mathrm{HCCH}$ tương đương nhau.

- Bệnh nhân suy tim phân suất tống máu $\geq$ $40 \%$ kèm HCCH thì chỉ số thể tích nhĩ trái tối thiểu có xu hướng lớn hơn những bệnh nhân không bi HCCH.

- Các phân suất làm rỗng nhĩ trái ở nhóm có
HCCH thấp hơn nhóm không có HCCH.

5.2. Mối liên quan giữa kích thước, chức năng nhĩ trái với một số dấu hiệu lâm sàng và cận lâm sàng đánh giá suy tim

- Chức năng dẫn máu, tống máu và chứa máu của nhĩ trái có xu hướng thấp hơn ở nhóm có phân độ NYHA trầm trọng hơn.

- Khi thất trái càng giãn và càng dày, chỉ số đường kính nhĩ trái và các chỉ số thể tích nhĩ trái có xu hướng tăng lên.

- Có mối tương quan tuyến tính nghịch biến giữa LAtEF với BMI theo phương trình: $Y=$ 0.91 . BMI + 78.91

\section{TÀI LIẸU THAM KHẢO}

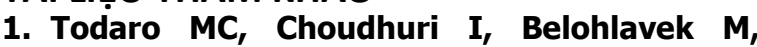
Jahangir A, Carerj S, Oreto $L$, et al. New echocardiographic techniques for evaluation of left atrial mechanics. Eur Heart J Cardiovasc Imaging. 2012;13(12):973-84.

2. Huang PL. A comprehensive definition for metabolic syndrome. Dis Model Mech. 2009;2(5-6):231-7.

3. Gupta A, Gupta V. Metabolic syndrome: what are the risks for humans? Bioscience trends. 2010;4(5):204-12.

4. Vinh PN. Khuyến cáo của hôi Tim mach Quốc gia Việt Nam về chẩn đoán và điều trị suy tim mạn: Cẩp nhât 2018. 2018.

5. Sulistiowati E, Sihombing M. NCEP-ATP III and IDF criteria for metabolic syndrome predict type 2 diabetes mellitus. Universa Medicina. 2016;35(1).

6. Bytyci I, Bajraktari G. Left atrial changes in early stages of heart failure with preserved ejection fraction. Echocardiography. 2016;33(10).

7. Berisha G, Bajraktari G, Ibrahimi P, Bytyçi I, Rexhepaj N, Elezi S, et al. Impaired Left Atrial Reservoir Function in Metabolic Syndrome Predicts Symptoms in HFpEF Patients. International Cardiovascular Forum Journal. 2015;4.

\section{PHÂN TÍCH MỘT SỐ YẾU TỐ LIÊN QUAN ĐẾN CHỈ ĐINHH ĐĂT NộI KHÍ QUẢN Ở BỆNH NHÂN NHỒI MÁU NÃO DIỆN RộNG BÁN CẦU}

\section{TÓM TẮT}

Mục tiêu: Phân tích một số yếu tố liên quan giữa đặc điểm lâm sàng, hình ảnh học và chỉ định đặt nội khí quản (NKQ) ở bệnh nhân nhồi máu não diện rộng

\section{${ }^{1}$ Bênh viện Bach Mai}

2Trường Đai học Y Hà Nọi

${ }^{3}$ Bênh Viên Đa khoa Của Đông.

Chịu trách nhiệm chính: Võ Hồng Khôi

Email: drvohongkhoi@yahoo.com.vn

Ngày nhận bài: 10.9.2021

Ngày phản biên khoa hoc: 15.10.2021

Ngày duyệt bài: 11.11.2021

\section{Võ Hồng Khôii ${ }^{1,2}$, Nguyễn Văn Quân ${ }^{3}$}

bán cầu. Đối tượng nghiên cứu: 69 bệnh nhân nhồi máu não diện rộng bán cầu, trong đó 38 bệnh nhân không đăt NKQ, 31 bệnh nhân có đặt NKQ điêu trị tại Trung tầm thần kinh Bệnh viện Bạch Mai từ tháng 8/2020-7/2021. Phương pháp nghiên cứu: Mô tả cắt ngang. Kết quả: Tuổi trung bình của nhóm bênh nhân nghiên cứu là $68,41 \pm 11,65$ tuổi, nam giới chiếm $60,9 \%$. Các triệu chứng lâm sàng khi khởi phát thường gặp là: liệt vận động $(100 \%)$, RL ngôn ngũ $(97,1 \%)$, đau đầu $(30,4 \%)$, buồn nôn/nôn $(30,4 \%)$, rối loạn ý thức $(60,9 \%)$, quay mắt quay đầu $(46,4 \%)$, rối loạn cơ tròn $(47,8 \%)$. Điểm NIHSS trung bình khi nhập viện là 19,0 $\pm 3,84$ điểm, điểm Glasgow trung bình lúc nhập viện là 12,9 $\pm 1,36$ điểm. Điểm ASPECT 